\title{
Prevalence of fungemia in a tertiary hospital: Analysis of the last decade
}

\author{
luísa Lima Castro ${ }^{1}$, Manuel Schütze ${ }^{2}$, Daniel Henrique Bücker ${ }^{3}$, Leonardo de Souza Vasconcellos ${ }^{4 *}$ \\ ${ }^{1}$ MD from Faculdade de Medicina, Universidade Federal de Minas Gerais (UFMG), Belo Horizonte, MG, Brazil \\ ${ }^{2}$ MD from Faculdade de Medicina, UFMG. MSc in Molecular Medicine from UFMG, Belo Horizonte, MG, Brazil \\ ${ }^{3}$ Biologist, degree from Universidade Federal de Rondônia. MSc in Genetics from UFMG. Employee of the Laboratory Medicine Service at Hospital das Clínicas, UFMG, Belo Horizonte, MG, Brazi \\ ${ }^{4} \mathrm{MSc}$ and PhD in Medicine from UFMG. Adjunct Professor, Department of Complementary Propedeutics, Faculdade de Medicina, UFMG. MD, Clinical Pathologist, Belo Horizonte, MG, Brazil
}

Study conducted by the Grupo de Pesquisa em Patologia Clínica/ Medicina Laboratorial (GPPCML) da Universidade Federal de Minas Gerais (UFMG), Belo Horizonte, MG, Brazil

Article received: $10 / 29 / 2014$ Accepted for publication: 11/3/2014

*Correspondence: Dpto. de Propedêutica Complementar da Faculdade de Medicina da UFMG Address: Av. Prof. Alfredo Balena, 190, sala 403, Santa Efigênia Belo Horizonte, MG - Brazil Postal code: 30130-100 leonardos_vasconcellos@yahoo.com.br

http://dx.doi.org/10.1590/1806-9282.62.04.315

\section{SUMMARY}

Introduction: The prevalence of nosocomial fungemia has increased worldwide, and mortality caused by this disease is high.

Objective: To assess progress in the last decade, and the prevalence and profile of fungal agents isolated in blood cultures performed in a tertiary university hospital. Method: All the results of blood cultures processed at Hospital das Clínicas, Universidade Federal de Minas Gerais (HC-UFMG), in the time intervals 20012003 and 2011-2013 were analyzed retrospectively. For each three-year period, the number of collected blood cultures, the overall positivity rate and the percentage of fungemia were recorded. In addition, all identified fungal species were cataloged. All blood samples were incubated in the BacT/ALERT ${ }^{\circledast}$ (bioMérieux) automation system.

Results: In 2001-2003, 34,822 samples were evaluated, with 5,510 (15.8\%) positive results. In 2011-2013, the number of blood cultures processed increased to 55,052 samples, with 4,873 (8.9\%) positive results. There was an increase in the number of positive cultures for fungi in the analyzed period (2001-2003: 4.16\%; 2011-2013: 5.95\%; $\mathrm{p}$ <0.001). Among the agents, candidemias were predominant, especially those caused by non-albicans Candida species (2001-2003: 57.64\%; 20112013: 65.17\%; $\mathrm{p}<0.05)$. There was also an increase in fungemia caused by other genera (2001-2003: 2.62\%; 2011-2013: 4.48\%; $\mathrm{p}<0.01$ ).

Conclusion: There was an increase in the prevalence of fungemia in the last decade at HC-UFMG. Although candidemias have been responsible for most of the cases, there has been an increase in fungemias caused by other species.

Keywords: Candida, non-albicans Candida, fungemia, tertiary health care, prevalence.

\section{INTRODUCTION}

The term fungemia indicates the presence of viable fungi in the bloodstream, confirmed by laboratory tests. Currently, over $80 \%$ of infections in the bloodstream, whether caused by fungi or bacteria, are acquired in hospitals or other medical care centers. ${ }^{1}$

Mortality among patients with nosocomial fungemia is high, reaching rates as high as 50 to $80 \%$, and has been attributed mainly to absence or inadequacy of initial antifungal therapy. ${ }^{2,3}$

The prevalence of hospital fungemia has increased in recent decades worldwide. ${ }^{3,4}$ Several studies have shown that the main risk factors for fungemias are prolonged steroid therapy, chemotherapy, malnutrition, malignan- cy, previous fungal colonization, dialysis, abdominal surgery and immunosuppression. ${ }^{5,6}$ Other determining factors for the increased occurrence of hospital fungemia are the growing use of broad-spectrum antibiotics and invasive technical procedures, such as central venous catheters, mechanical ventilation, parenteral nutrition, and the growing number of organ transplants., ${ }^{2,4,7}$

The fungus most commonly isolated in the blood of patients with fungemia worldwide is Candida albicans. ${ }^{2,3,8,9}$ Pien et al. assessed blood cultures from 1,706 patients in US hospitals, and C. albicans was the main fungus found. ${ }^{1}$ Costa et al., in a study conducted in São Paulo, Brazil, reported that C. albicans was responsible for $50 \%$ of the cases of nosocomial fungemia. ${ }^{9}$ According to Cisterna et al., 
in a multicentric study carried out in Spain, C. albicans caused $49.08 \%$ of the infections, followed by C. parapsilosis (20.73\%), C. glabrata (13.61\%) and C. tropicalis (10.77\%). ${ }^{10}$

The incidence of non-albicans Candida species has shown significant increase in recent decades. ${ }^{3}$ As susceptibility to antifungal drugs varies among species of Candida, it is important to know the prevalence of each of them in hospitals. ${ }^{11}$ Early distinction between candidemia and blood infection by other fungi is essential for effective therapy. ${ }^{4}$

In Brazil, epidemiological surveys of fungemias in communities and hospitals have become increasingly frequent. Motta et al., in a study conducted at the Faculdade de Medicina, Universidade de São Paulo (FMUSP), Hospital das Clínicas, reported a $4 \%$ prevalence of fungemia in blood cultures performed in 2006, with approximately $86 \%$ of cases related to species of the Candida genus. The species isolated most often were C. albicans (52.2\%), C. parapsilosis (22.1\%), C. tropicalis (14.7\%), C. glabrata (6.6\%). ${ }^{12}$

In addition to damage to the health of the population, fungemias also cause economic losses to public health systems. Typically, antifungal treatments are long, which increases the length of hospital stay and the cost of drugs. ${ }^{13-16}$ In a recent article, Bloos et al. demonstrated the higher financial cost in patients hospitalized due to candidemia compared with sepse caused by other agents. ${ }^{15}$

Because of the inconvenience caused by this disease, each health care institution should know the profile of agents that cause fungemia in its population. This is vital not only for epidemiological purposes, but especially for care and therapy, serving also as parameter for implementation of preventive measures and hospital infection control.

Our study aims to compare prevalence progression and the profile of fungal species found in blood cultures of patients admitted to the Universidade Federal de Minas Gerais (UFMG), Hospital das Clínicas, Brazil, in the last decade.

\section{Method}

All the results of blood cultures processed in the sector of Microbiology, Laboratory Medicine Service of Hospital das Clínicas, Universidade Federal de Minas Gerais (HC-UFMG), in 2001-2003 and 2011-2013 were assessed. For each period, the number of samples collected, the overall positivity rate and the percentage of fungemia were recorded. In addition, all identified fungal species were cataloged.

In order to perform the blood cultures at the HCUFMG, blood samples were taken after skin antisepsis with $0.5 \%$ alcoholic chlorhexidine. The number of samples varied according to the physician's discretion. Usually, three samples were collected from different anatom- ical sites in the case of adult patients, and a single sample for children. For adults, $16 \mathrm{~mL}$ to $20 \mathrm{~mL}$ of blood were collected from each sample, distributed into two bottles: Green lid (aerobic) and orange lid (anaerobic). For the children, the volume of blood varied from $1 \mathrm{~mL}$ to $5 \mathrm{~mL}$, collected in a single jar with a yellow lid.

The blood culture bottles were transported to the Microbiology sector and incubated in a BacT/ALERT ${ }^{\circledR}$ (bioMérieux) device. This is an automated system for incubation and identification of microbial growth, based on the colorimetric detection of $\mathrm{CO}_{2}$ through sensors positioned on the bottom of culture flasks. Growth of microorganisms increases $\mathrm{CO}_{2}$, showing positivity in the bottle.

The incubation time for antimicrobial growth was based on recommendations by the Clinical and Laboratory Standards Institute (CLSI). Between 2001 and 2003, blood cultures lacking growth of microorganisms within seven days of incubation were considered negative. In case of suspected fungemia reported in the medical test request form, the incubation period would be increased to 30 days. ${ }^{16,17}$ From 2011 to 2013, in turn, according to the recommendations in force, incubation periods were reduced to 5 and 14 days, respectively. ${ }^{16,17}$

The positive samples were subjected to Gram staining and morphological analysis using optical microscopy. After the identification of yeast-form or mycelial filaments using Gram staining, the samples were seeded on glass slides containing a Sabouraud medium and incubated at $37^{\circ} \mathrm{C}$ to determine the species. For yeast-form growth, the following tests were performed to identify Candida: resistance to cycloheximide, germ tube formation, microculture and physiological fermentation. Whenever Cryptococcus was suspected, urea test and inoculation in Niger culture medium were performed. Mycelial fungi were subjected to microculture in Sabouraud's agar. Once the fungi were identified, the results were passed on to the Laboratory Informatics System and electronically released for consultation by the requesting physician and the patient.

For statistical analysis of the data, a two-sided chisquare test of the periods analyzed was adopted. P-value $<0.05$ was considered significant.

\section{RESULTS}

From January 2001 to December 2003, and from January 2011 to December 2013, 89,874 blood samples were analyzed in the sector of Microbiology, Laboratory Medicine Service of HC-UFMG.

In 2001-2003, 34,822 blood samples were analyzed, of which 5,510 (15.8\%) yielded positive results. Among 
the latter, fungi were identified in 229 (16.4\%) samples. In 2011-2013, 55,052 blood culture bottles were analyzed, with 4,873 (8.9\%) positive samples, of which 290 (5.95\%) contained fungi (Figure 1).

Among the isolated fungal species, prevalence of candidemias was observed: $97.38 \%$ (2001-2003) and 95.52\% (2011-2013). The main species isolated in both periods was Candida albicans: 39.74\% (2001-2003) and 30.34\% (2011-2013). There was an increase in the number of positive cultures for fungi in the analyzed period (2001-2003: 4.16\%; 2011-2013: $5.95 \% ; \mathrm{p}<0.001)$. There was also an increase in the number of non-albicans Candida species (2001-2003: 57.64\%; 20112013: 65.17\%; $\mathrm{p}<0.05)$ and in non-Candida genera (20012003: 2.62\%; 2011-2013: 4.48\%; $\mathrm{p}<0.01)$. The fungi isolated in each analyzed period are shown in Table 1.

TABLE 1 Fungal species isolated from blood cultures performed at the Laboratory Medicine Service of Hospital das Clínicas, Universidade Federal de Minas Gerais, Brazil, in 2001-2003 and 2011-2013.

\begin{tabular}{lllllll} 
Species & \multicolumn{2}{l}{$\mathbf{2 0 0 1 - 2 0 0 3}$} & \multicolumn{2}{l}{$\mathbf{2 0 1 1 - 2 0 1 3}$} & \multicolumn{2}{l}{ Total } \\
\hline & $\mathbf{N}$ & $\mathbf{\%}$ & $\mathbf{N}$ & $\mathbf{\%}$ & $\mathbf{N}$ & $\mathbf{\%}$ \\
\hline Candida albicans & 91 & 39.7 & 88 & 30.3 & 179 & 34.5 \\
\hline Candida glabrata & 1 & 0.4 & 7 & 2.4 & 8 & 1.5 \\
\hline Candida guilliermondii & 3 & 1.3 & 4 & 1.4 & 7 & 1.3 \\
\hline Candida kefyr & 0 & 0 & 2 & 0.7 & 2 & 0.4 \\
\hline Candida krusei & 0 & 0 & 9 & 3.1 & 9 & 1.7 \\
\hline Candida parapsilosis & 60 & 26.2 & 79 & 27.2 & 139 & 26.8 \\
\hline Candida spp. & 29 & 12.7 & 24 & 8.3 & 53 & 10.2 \\
\hline Candida tropicalis & 39 & 17 & 64 & 22.1 & 103 & 19.8 \\
\hline Cryptococcus neoformans & 3 & 1.3 & 7 & 2.4 & 10 & 1.9 \\
\hline Cryptococcus spp. & 3 & 1.3 & 4 & 1.4 & 7 & 1.3 \\
\hline Fusarium sp. & 0 & 0 & 2 & 0.7 & 2 & 0.4 \\
\hline Total & 229 & 100 & 290 & 100 & 519 & 100 \\
\hline N:Absolute no & & & & & &
\end{tabular}

\section{Discussion}

Candida spp. is found in the gastrointestinal tract in 20 to $80 \%$ of the healthy adult population. These microorganisms can become pathogenic if there are changes in host defense mechanisms. Candidemia has a high incidence in tertiary hospitals, with overall mortality of $60 \%$. Rapid detection of the etiological agent causing the infection is of fundamental importance to allow early adjustment of treatment and hence, the reduction of hospital mortality by fungemia. ${ }^{4}$

The HC-UFMG is a teaching hospital that offers public and general care, health assistance, research services

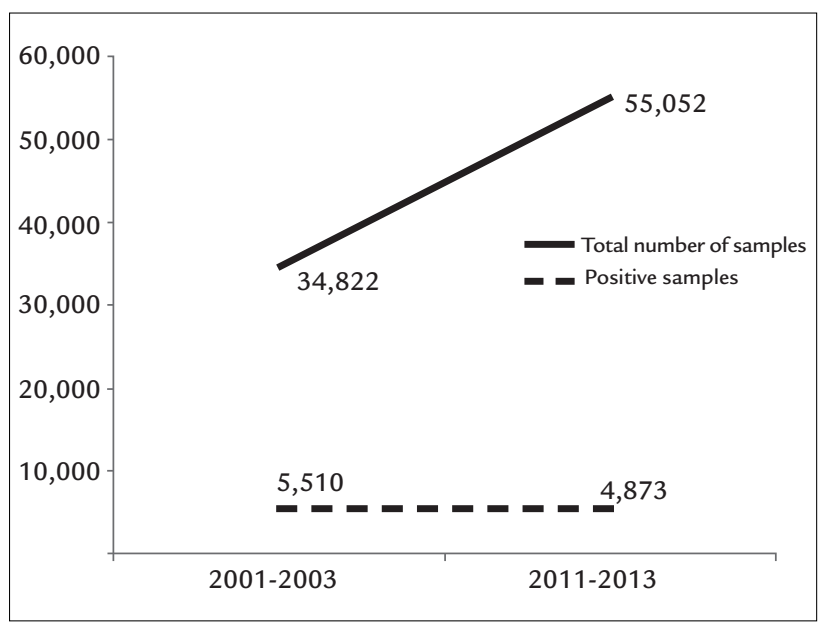

FIGURE 1 Number of total and positive samples of blood cultures, Laboratory Medicine Service of Hospital das Clínicas, Universidade Federal de Minas Gerais, Brazil, in 2001-2003 and 2011-2013.

and further training. It admits patients of the Unified Health System (SUS) only and is located in Belo Horizonte, Minas Gerais, Brazil. The HC-UFMG is a reference hospital in the municipal and state healthcare spheres for medium and high-complexity procedures, mainly in oncohematologic, infectious and parasitic, endocrine-metabolic, and mother and child diseases, as well as transplantation of organs and tissues. The HC-UFMG hospital complex has 511 beds; it includes one central building and seven other buildings for out- and in-patient care comprising all specialties and sub-specialties covered by the SUS system. Each month in these facilities, about 2,300 emergency room visits, 1000 hospitalizations, 24,000 outpatient visits and 155,000 laboratory tests take place. ${ }^{18}$

In this study, the authors observed an increased incidence of fungemia in the last decade. This increase was consistent with epidemiological data from other national and international hospitals. ${ }^{6,13,19-21}$ The increased prevalence of fungemia in hospital services may be related to advances in health care, which allowed greater survival of immunosuppressed patients. ${ }^{19}$ The frequent use of invasive instruments and materials in hospital care, and the indiscriminate use of broad-spectrum antimicrobials also contributed to the increase in fungemia. ${ }^{2,19}$

The increase in the percentage of fungemia diagnosed in the last decade can be more significant, considering that false-negative results can occur if the minimum incubation time for growth of fungal species is not observed. At HC-UFMG, only samples reported as suspected fungemia were subjected to longer incubation times, either from 7 to 30 days (2001-2003) or from 5 to 14 days (2011- 
2013). ${ }^{16}$ Unfortunately, the possibility of fungemia was not always informed on the request form for laboratory testing. In these cases, the samples were discarded early, probably hindering a proper diagnosis of fungemia.

We must also bear in mind that blood culture is a test that has intermediate sensitivity to detect fungal species, and may exhibit a sensitivity of only $50 \%$ for candidemias, for example. ${ }^{22}$ Therefore, the prevalence of fungemia detected in the HC-UFMG, and in other hospitals, can be falsely lower than the actual prevalence of this infection.

The most frequent microorganism in this study was Candida spp., which accounted for almost all of the isolated fungi, and Candida albicans, which was the most frequent species. These results are in agreement with other studies. ${ }^{2,3,8,22}$

Even though C. albicans was the most prevalent species, our results revealed an increase in the prevalence of other fungal species, especially non-albicans Candida spp. Other authors have demonstrated high rates of candidemia caused by non-albicans species. ${ }^{3,23}$ The reasons for the emergence of other species have not been clarified. However, some risk factors are strongly associated to fungemia by certain species. C. parapsilosis has been linked to vascular catheter and parenteral nutrition. ${ }^{24,25} \mathrm{C}$. tropicalis was associated with cancer and neutropenia. ${ }^{26,27} \mathrm{C}$. krusei has been associated with prior use of azoles, neutropenia and hematologic malignancies. ${ }^{28} \mathrm{C}$. glabrata has been associated with prior use of azoles, and transplants of solid organ and hematopoietic cells., ${ }^{2,-31}$

Some Candida spp. were isolated between 2011 and 2013: Candida kefyr, Candida krusei and Fusarium sp. Recent isolation of C. glabrata can represent a trend of increased incidence of this species in Brazil, already reported in São Paulo between 2006 and 2010, ${ }^{32}$ whose mortality seems higher than that of C. albicans. ${ }^{3}$

An interesting fact is the increased prevalence of genera other than Candida, whose mortality rate is higher than that found in candidemias. ${ }^{4}$ Previous colonization by these fungal species, collagen diseases and dialysis are risk factors associated with fungemia caused by non-Candida genera. ${ }^{4}$

Laboratory diagnosis of fungemia is extremely important to establish proper treatment and to reduce patient morbidity and mortality. Knowledge on the most prevalent species responsible for cases of fungemia within the service will allow the attending physician to initiate the most appropriate empiric therapy, as well as the analysis of a possible impact of new anti-fungal drugs introduced to the market on the profile of hospital fungemias.

\section{Conclusion}

There was an increase in the prevalence of fungemia among patients treated at the HC-UFMG in the last decade. Candidemias represented almost all cases, but there was an increase in fungemias caused by other genera.

\section{Resumo}

Prevalência de fungemia em um hospital terciário: análise da última década

Introdução: a prevalência de fungemia hospitalar tem aumentado em todo o mundo e a mortalidade por essa afecção é elevada.

Objetivo: avaliar a evolução, na última década, da prevalência e do perfil dos agentes fúngicos isolados em hemoculturas realizadas em um hospital universitário terciário. Método: foram analisados retrospectivamente todos os resultados de hemocultura processados no Hospital das Clínicas da Universidade Federal de Minas Gerais (HC-UFMG), entre os períodos de 2001-2003 e de 2011-2013. Para cada triênio foram registrados o número de hemoculturas coletadas, o percentual de positividade geral e o percentual de fungemia. Também foram catalogadas todas as espécies fúngicas identificadas. Todas as amostras sanguíneas foram incubadas no sistema de automação BacT/ALERT ${ }^{\circledast}$ (bioMérieux).

Resultados: entre 2001-2003, foram avaliadas 34.822 amostras, sendo 5.510 (15,8\%) positivas. Entre 2011-2013, o número de hemoculturas processadas aumentou para 55.052 amostras, sendo 4.873 (8,9\%) positivas. Observou-se um aumento do número de culturas positivas para fungos no período analisado (2001-2003: 4,16\%; 2011-2013: 5,95\%; $\mathrm{p}<0,001)$. Dentre os agentes, as candidemias foram predominantes, principalmente por espécies de Candida não albicans (2001-2003: 57,64\%; 2011-2013: 65,17\%; $\mathrm{p}<0,05)$. Houve também aumento da fungemia por outros gêneros (2001-2003: 2,62\%; 2011-2013: 4,48\%; $\mathrm{p}<0,01$ ).

Conclusão: houve aumento da prevalência de fungemia na última década no HC-UFMG. Embora as candidemias tenham sido responsáveis pela maioria dos casos, houve aumento de fungemias causadas por outras espécies.

Palavras-chave: Candida, Candida não albicans, fungemia, atenção terciária à saúde, prevalência.

\section{References}

1. Pien BC, Sundaram P, Raoof N, Costa SF, Mirrett S, Woods CW, et al. The clinical and prognostic importance of positive blood cultures in adults. Am J Med. 2010; 123(9):819-28. 
2. Anunnatsiri S, Chetchotisakd P, Mootsikapun P. Fungemia in non-HIVinfected patients: a five-year review. Int J Infect Dis. 2009; 13(1):90-6.

3. Colombo AL, Guimarães T, Silva LR, de Almeida Monfardini LP, Cunha AK, Rady P, et al. Prospective observational study of candidemia in São Paulo, Brazil: incidence rate, epidemiology and predictors of mortality. Infect Control Hosp Epidemiol. 2007; 28(5):570-6.

4. Yamamoto M, Takakura S, Hotta G, Matsumura Y, Matsushima A, Nagao $\mathrm{M}$, et al. Clinical characteristics and risk factors of non-Candida fungaemia. BMC Infect Dis. 2013; 13:247-53.

5. Dóczi I, Pető Z, Fodor E, Bereczki L, Nagy E, Hajdú E. Evaluation of fungaemia infections in a Hungarian university hospital between 1996 and 2009. Acta Microbiol Immunol Hung. 2012; 59(1):29-41.

6. Rosas RC, Salomão R, da Matta DA, Lopes HV, Pignatari AC, Colombo AL. Bloodstream infections in late-stage acquired immunodeficiency syndrome patients evaluated by a lysis centrifugation system. Mem Inst Oswaldo Cruz. 2003; 98(4):529-32.

7. Asmundsdóttir LR, Erlendsdóttir H, Gottfredsson M. Increasing incidence of candidemia: results from a 20-year nationwide study in Iceland. J Clin Microbiol. 2002; 40(9):3489-92.

8. Almirante B, Rodríguez D, Park BJ, Cuenca-Estrella M, Planes AM, Almela M, et al.; Barcelona Candidemia Project Study Group. Epidemiology and predictors of mortality in cases of Candida bloodstream infection: results from population-based surveillance, Barcelona, Spain, from 2002 to 2003. J Clin Microbiol. 2005; 43(4):1829-35.

9. Costa SF, Marinho I, Araújo EA, Manrique AE, Medeiros EA, Levin AS. Nosocomial fungaemia: a 2-year prospective study. J Hosp Infect. 2000; 45(1):69-72.

10. Cisterna R, Ezpeleta G, Telleria O; Spanish Candidemia Surveillance Group. Nationwide sentinel surveillance of bloodstream Candida infections in 40 tertiary care hospitals in Spain. J Clin Microbiol. 2010; 48(11):4200-6.

11. Lai CC, Gau SJ, Tan CK. Distribution of Candida species causing bloodstream infections. J Microbiol Immunol Infect. 2012; 45(2):161-2.

12. Motta AL, Almeida GMD, Almeida Júnior JN, Burattini MN, Rossi F. Candidemia epidemiology and susceptibility profile in the largest Brazilian teaching hospital complex. Braz J Infect Dis. 2010; 14(5):441-8.

13. Sampaio Camargo TZ, Marra AR, Silva CV, Cardoso MF, Martino MD, Camargo LF, et al. Secular trends of candidemia in a tertiary care hospital. Am J Infect Control. 2010; 38(7):546-51.

14. Rosenthal VD, Guzman S, Migone O, Crnich CJ. The attributable cost, length of hospital stay, and mortality of central line-associated bloodstream infection in intensive care departments in Argentina: a prospective, matched analysis. Am J Infect Control. 2003; 31(8):475-80.

15. Bloos F, Bayer O, Sachse S, Straube E, Reinhart K, Kortgen A. Attributable costs of patients with candidemia and potential implications of polymerase chain reaction-based pathogen detection on antifungal therapy in patients with sepsis. J Crit Care. 2013; 28(1):2-8.

16. Clinical and Laboratory Standards Institute/National Committee for Clinical Laboratory Standards - CLSI. Principles and Procedures for Blood Cultures; Approved Guideline. CLSI document M47-A. Wayne: Clinical and Laboratory Standards Institute, 2007

17. Clinical and Laboratory Standards Institute/National Committee for Clinical Laboratory Standards - CLSI. Reference method for broth dilution susceptibility testing of yeasts: approved standard. 3.ed. Wayne: Clinical and Laboratory Standards Institute, 2008.

18. Nossa História - Hospital das Clínicas UFMG. [cited 2014 Oct 12]. Available from: http://www.hc.ufmg.br/institucional/historia.

19. Giolo MP, Svidzinski TIE. Fisiopatogenia, epidemiologia e diagnóstico laboratorial da candidemia. J Bras Patol Med Lab. 2010; 46(3):225-34.

20. Banerjee SN, Emori TG, Culver DH, Gaynes RP, Jarvis WR, Horan T, et al. Secular trends in nosocomial primary bloodstream infections in the United States, 1980-1989. National Nosocomial Infections Surveillance System. Am J Med. 1991; 91(3B):86S-9S.

21. Velasco E, Thuler LCS, Martins CAS, Nucci M, Dias LMC, Gonçalves VMSC. Epidemiology of bloodstream infections at a cancer center. Sao Paulo Med J. 2000; 118(5):131-8

22. Pfaller MA, Diekema DJ. Epidemiology of invasive candidiasis: a persistent public health problem. Clin Microbiol Rev. 2007; 20(1):133-63.

23. Colombo AL, Nucci M, Salomão R, Branchini ML, Richtmann R, Derossi A, et al. High rate of non-albicans candidemia in Brazilian tertiary care hospitals. Diagn Microbiol Infect Dis. 1999; 34(4):281-6.

24. Clark TA, Slavinski SA, Morgan J, Lott T, Arthington-Skaggs BA, Brandt $\mathrm{ME}$, et al. Epidemiologic and molecular characterization of an outbreak of Candida parapsilosis bloodstream infections in a community hospital. J Clin Microbiol. 2004; 42(10):4468-72.

25. Levy I, Rubin LG, Vasishtha S, Tucci V, Sood SK. Emergence of Candida parapsilosis as the predominant species causing candidemia in children. Clin Infect Dis. 1998; 26(5):1086-8.

26. Muñoz P, Giannella M, Fanciulli C, Guinea J, Valerio M, Rojas L, et al. Candida tropicalis fungaemia: incidence, risk factors and mortality in a general hospital. Clin Microbiol Infect. 2011; 17(10):1538-45

27. Nucci M, Colombo AL. Candidemia due to Candida tropicalis: clinical, epidemiologic, and microbiologic characteristics of 188 episodes occurring in tertiary care hospitals. Diagn Microbiol Infect Dis. 2007; 58(1):77-82.

28. Marr KA, Seidel K, White TC, Bowden RA. Candidemia in allogeneic blood and marrow transplant recipients: evolution of risk factors after the adoption of prophylactic fluconazole. J Infect Dis. 2000; 181(1):309-16.

29. Trick WE, Fridkin SK, Edwards JR, Hajjeh RA, Gaynes RP; National Nosocomial Infections Surveillance System Hospitals. Secular trend of hospital-acquired candidemia among intensive care unit patients in the United States during 1989-1999. Clin Infect Dis. 2002; 35(5):627-30.

30. Aquino VR, Lunardi LW, Goldani LZ, Barth AL. Prevalence, susceptibility profile for fluconazole and risk factors for candidemia in a tertiary care hospital in southern Brazil. Braz J Infect Dis. 2005; 9(5):411-8.

31. Ortega M, Marco F, Soriano A, Almela M, Martínez JA, López J, et al. Candida species bloodstream infection: epidemiology and outcome in a single institution from 1991 to 2008. J Hosp Infect. 2011; 77(2):157-61.

32. Moretti ML, Trabasso P, Lyra L, Fagnani R, Resende MR, de Oliveira Cardoso LG, et al. Is the incidence of candidemia caused by Candida glabrata increasing in Brazil? Five-year surveillance of Candida bloodstream infection in a university reference hospital in southeast Brazil. Med Mycol. 2013; 51(3):225-30 